06,11

\title{
Влияние глубины переохлаждения на релаксацию доменной структуры триглицинсульфата
}

\author{
() О.Ю. Мазур, Л.И. Стефранович
}

Институт фризики горных процессов НАН Украины,

Днепр-5, Украина

E-mail: o.yu.mazur@gmail.com

Поступила в Редакцию 11 марта 2019 г.

В окончательной редакции 11 марта 2019 г.

Принята к публикации 2 апреля 2019 г.

Рассмотрен процесс формирования и эволюции доменной структуры в кристаллах триглицинсульфата (ТГС) после быстрого охлаждения в окрестности точки Кюри $T_{C}$. Получено аналитическое выражение для временной зависимости характерного среднего размера домена, которое позволяет проследить процесс укрупнения доменной структуры на всех стадиях ее релаксации к состоянию термодинамического равновесия. Показано, что средний размер домена растет по закону квадратного корня, что хорошо согласуется с известными экспериментальными данными. Установлено, что скорость роста доменной структуры зависит от глубины переохлаждения образца. Полученная в работе зависимость характерного среднего размера домена от времени позволяет определить радиус межмолекулярного взаимодействия исследуемых кристаллов.

Ключевые слова: быстрозакаленная сегнетоэлектрическая система, глубина переохлаждения, эврлюция доменной структуры, релаксация, триглицинсульфат.

DOI: 10.21883/FTT.2019.08.47972.412

\section{1. Введение}

Независимо от причин, приведших систему в неравновесное состояние, перевод такой системы как сегнетоэлектрический кристалл в состояние, далекое от термодинамического равновесия, сопровождается возникновением локальных областей спонтанной поляризации. Эти области эволюционируют со временем, что, в конечном итоге, приводит к формированию той или иной доменной структуры (ДС).

Перестройки ДС могут носить как обратимый, так и необратимый характер. В случае вынужденной переполяризации доменной структуры температурным отжигом или воздействием постоянного электрического поля сформировавшаяся доменная структура оказывается нестабильной и постепенно возвращается к исходному состоянию. Эксперименты, проведенные на кристаллах триглицинсульфата (ТГС), показывают, что это происходит в течение $140-160 \mathrm{~h}$ [1]. Анализ эволюции доменов на стадии их формирования приобретает особую актуальность при переходе к наноразмерному диапазону, где может сказаться влияние флуктуационных эффектов.

Несмотря на то, что процесс формирования ДС, в особенности, на начальных стадиях, носит случайный характер, имеются успешные попытки его теоретического описания на примере сегнетоэлектриков типа смещения, используя микроскопический подход и флуктуационную теорию [2]. Данная работа посвящена исследованию эволюции доменной структуры сегнетоэлектриков, которая возникает на стадии релаксации после быстрого охлаждения образца ниже точки Кюри $T_{C}$, в сегнетоэлектриках, испытывающих фазовые переходы второго рода типа порядок-беспорядок. Цель работы: проследить позднюю стадию эволюции полидоменного состояния сегнетоэлектрика в отсутствие внешних воздействий. Влияние внешних воздействий на процесс формирования ДС было изучено нами ранее в работах $[3,4]$.

\section{2. Общее описание модели}

Как известно, сегнетоэлектрическая поляризация возникает при переходе через температуру Кюри $T_{C}$. Если охлаждение происходит быстро, то система не успевает перейти в состояние термодинамического равновесия, вследствие чего в разных частях кристалла спонтанно возникают области с отличной от нуля поляризацией - зародыши сегнетоэлектрических доменов. Размер неоднородностей поляризации, возникших на начальной стадии, существенно зависит от предыстории образца [3].

Как показывают многочисленные эксперименты [5-8], неравновесная доменная структура не остается неизменной, а эволюционирует со временем в процессе релаксации системы из неравновесного состояния к состоянию термодинамического равновесия. Это явление требует теоретического объяснения. В связи с этим была поставлена задача по теоретическому исследованию процесса эволюции сильнонеравновесной доменной структуры, которая образуется в результате быстрого охлаждения образца из парафазы в сегнетофазу. Скорость охлаждения образца предполагается достаточно большой, чтобы в процессе его охлаждения система не успела перейти в состояние термодинамического равновесия, но в то же время является сравнительно малой, 
чтобы разрушить образец в процессе его охлаждения. В известных нам экспериментальных работах [5-7] это достигается использованием скоростей охлаждения в диапазоне $1-10 \mathrm{~K} / \mathrm{min}$. Быстро охладив систему ниже температуры Кюри $T_{C}$, можно наблюдать „растянутый во времени“ фазовый переход и проследить процесс упорядочения сегнетоэлектрической системы на всех стадиях ее формирования.

В качестве объекта исследований нами был выбраны кристаллы ТГС. Это один из немногих одноосных сегнетоэлектриков с простой 180-градусной ДС, испытывающий фазовый переход второго рода типа порядокбеспорядок. К тому же имеется ряд экспериментальных работ по исследованию релаксации быстро охлажденных кристаллов ТГС вблизи температуры фазового перехода. Поэтому он удобен для последующей экспериментальной верификации полученных теоретически результатов.

Для описания процесса упорядочения неравновесной сегнетоэлектрической доменной структуры вблизи $T_{C}$ был использован феноменологический подход на основе теории фазовых переходов второго рода Ландау, развитый в работе [3]. В рамках этого подхода неравновесный термодинамический потенциал был представлен в виде функционала Гинзбурга-Ландау по степеням параметра порядка $\pi_{i}$, в качестве которого выступала проекция вектора поляризации на одно из кристаллографических направлений $P_{z}$. С помощью уравнения ЛандауХалатникова было получено уравнение, описывающее пространственно-временную эволюцию случайного поля параметра порядка. Для описания процессов упорядочения по всему объему образца, а не в отдельном домене, было удобно перейти на усредненное описание, вводя среднее значение параметра порядка $\langle\pi(\mathbf{r}, \tau)\rangle \equiv \bar{\pi}(\tau)$ и двухточечную корреляционную функцию (коррелятор второго порядка) [3]. В результате корреляционного анализа была получена временная зависимость безразмерного корреляционного радиуса $r_{c}=r_{c}(\tau)$. Последний можно отождествить со средним характерным размером домена. Для сравнения с экспериментом его удобно преобразовать к размерному виду

$$
\bar{R}_{d}(t)=\frac{r_{0}}{\sqrt{\alpha}}\left(r_{c}^{2}(0)+\frac{2 t}{3 t^{*}}\right)^{1 / 2},
$$

где $r_{0}-$ радиус межмолекулярного взаимодействия, который для кристаллов ТГС имеет порядок $10^{-9}-10^{-10} \mathrm{~m}$, а $r_{c}(0)$ - безразмерный начальный корреляционный радиус. Характерное время $t^{*}$ определяется формулой Аррениуса

$$
t^{*}=\frac{\hbar}{k_{B} T_{D}} \exp \left(\frac{Q}{k_{B} T_{1}}\right),
$$

где $\hbar=1.054 \cdot 10^{-34} \mathrm{~J} \cdot \mathrm{s}-$ постоянная Планка, $k_{B}=1.38 \cdot 10^{-23} \mathrm{~J} / \mathrm{K}-$ постоянная Больцмана, $T_{D}-$ температура Дебая, $Q-$ энергия активации.
Как видно из выражения (1), средний размер домена $\bar{R}_{d}(t)$ зависит не только от времени и размера начальных неоднородностей, но также от параметра переохлаждения $\alpha$. Полученная зависимость (1) не только позволяет описать кинетику роста доменов в неравновесной области, но и имеет фундаментальный характер. Она содержит фактически один неизвестный параметр радиус межмолекулярного взаимодействия $r_{0}$, который в наших расчетах выбирается из физических соображений. Но на основе полученной зависимости (1) и экспериментальных наблюдений размера растущих доменов полидоменной структуры он может быть точно вычислен для конкретного сегнетоэлектрика, охлажденного до определенной температуры $T_{1}<T_{C}$.

\section{3. Оценка размеров доменов неравновесной доменной структуры на стадии релаксации образца к состоянию термодинамического равновесия}

Насколько нам известно, первые эксперименты по изучению кинетики упорядочения быстроохлажденных образцов ТГС были проведены в Японии еще в 1989 г. [5]. В указанной работе глубина переохлаждения образца составляла $25 \mathrm{~K}$, т.е. по сути, изучалась релаксация неравновесной ДС при значительных величинах переохлаждения образца ниже температуры фазового перехода. Несмотря на то, что при таком глубоком переохлаждении имеет место сравнительно быстрый переход системы к термодинамическому равновесию, уже этот эксперимент показал, что исследуемый кристалл ТГС не сразу переходит к термодинамическому равновесию. Он некоторое время продолжает оставаться термодинамически нестабильным и, как следствие, достаточно чувствительным к внешним воздействиям таким, например, как внешнее электрическое поле. При этом доменная структура сохраняет тенденцию роста на протяжении часа [5]. Эксперименты в этом направлении возобновились только в 2000 г. в КНР [6], где эволюция доменной структуры в кристаллах ТГС изучалась чуть ниже температуры $T_{C}$. Основной целью этих экспериментов было выяснение роли глубины переохлаждения на степень неоднородности доменной структуры. После быстрого охлаждения кристалла ТГС до определенной температуры $T_{1}<T_{C}$ делались лишь мгновенные снимки ДС в фиксированные моменты времени, но кинетика в целом не изучалась [6].

Используя зависимость (1), мы проанализировали во времени весь процесс эволюции ДС для температур закалки, отвечающих глубинам переохлаждения, использованным авторами [6] в своих экспериментах, и установили средний размер домена в определенные моменты времени. Модельные расчеты проводились с учетом характерных физических параметров кристалла ТГС: температура Дебая $T_{D}=463 \mathrm{~K}$ [9], энергия активации 

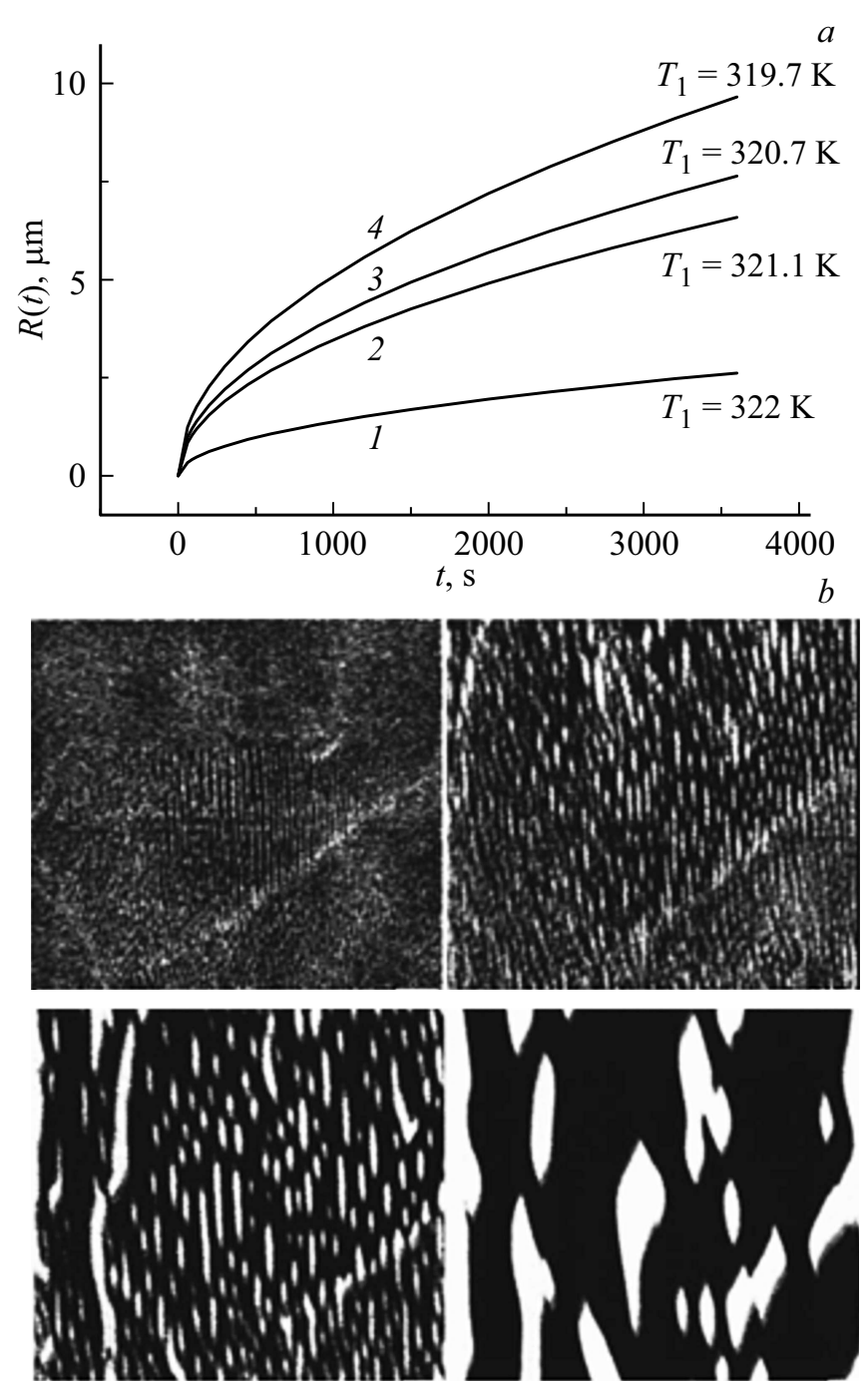

Рис. 1. $a-$ временные зависимости среднего размера доменов для кристалла ТГС, построенные на основе аналитического выражения (1). Кривые $1-4$ отвечают температурам наблюдения $T_{1}: 322,321.1,320.7,319.7 \mathrm{~K}$ соответственно; $b-$ мгновенные снимки релаксирующей доменной структуры ТГС из работы [6]; фотографии отвечают точкам на рис. 1, $a$ соответственно.

$Q=0.46 \mathrm{eV}[10]$, радиус межмолекулярного взаимодействия $r_{0}=5 \cdot 10^{-9} \mathrm{~m}$ [11]. Параметр переохлаждения определяется, как $\alpha=C /\left(T_{C}-T_{1}\right)$, где $C=2408 \mathrm{~K}-$ постоянная Кюри-Вейса [12], а $T_{C}=322.16 \mathrm{~K}$ - температура Кюри [11].

На рис. 1 изображены теоретические кривые, построенные с помощью зависимости (1) (рис. 1,a) и соответствующие им мгновенные снимки доменной структуры (рис. 1,b) [6]. Чем глубже переохлажден образец, тем больше средний размер домена (кривые $1-4$ на рис. $1, a)$, что согласуется с экспериментальными данными (рис. 1,b) [6]. На начальной стадии эволюции неравновесной системы, в особенности при быстрых степенях охлаждения, как правило, формируются до- мены малых размеров. Из теории фазовых переходов второго рода в металлических сплавах известно [13], что чем глубже закалена система в область неустойчивости однородного состояния, тем большая термодинамическая сила действует на систему, чтобы сформировать её неоднородности (в нашем случае - это неоднородности поляризации). Именно этим, по-видимому, и объясняется более быстрый рост среднего доменного размера на начальной стадии релаксации при больших степенях переохлаждения. А вот на поздних стадиях релаксации рост размера доменов (известный как „коалесценция“) можно объяснить слиянием доменов или поглощения малых доменов крупными. Поэтому вдали от $T_{C}$ (кривая 4 на рис. $1, a$ ) средний размер домена растет быстрее, чем вблизи $T_{C}$ (кривая 1 на рис. $1, a$ ). По истечении некоторого времени образованная неоднородная доменная структура полосчатого вида замедляет свой рост, а теоретическая кривая $\bar{R}_{d}(t)$ выходит на насыщение (рис. 1, $a$ ).

Работы [7, 14-16] также посвящены экспериментальному изучению кинетики упорядочения доменной структуры ТГС вблизи $T_{C}$. В этих работах на мгновенных снимках фиксировалось состояние релаксирующей ДС в разные моменты времени при быстрой закалке системы до температуры $T_{1}$ изотермической выдержки. Используя выражение (1), нами были построены теоретические кривые роста ДС для разных параметров переохлаждения и проведен сравнительный анализ полученных результатов с экспериментальными данными (рис. 2). Как и в работе [6], здесь прослеживается аналогичная зависимость скорости роста среднего размера домена от глубины переохлаждения, которая подчиняется корневой зависимости от времени (1). Скорость же укрупнения ДС связана с глубиной переохлаждения системы законом обратного корня $\dot{\bar{R}}_{d} \sim 1 / \sqrt{\alpha}$.

Сравнение теоретических и экспериментальных данных показывает, что реальный размер домена слегка превышает теоретически рассчитанные значения (рис. 2, $a-d)$. Это может быть связано, по-видимому, с неточным подбором фундаментальных параметров из физических соображений, ввиду отсутствия данных об их реальном значении, в частности, радиуса межмолекулярного взаимодействия $r_{0}$. Второй причиной может быть то, что растущие домены полосчатой полидоменной структуры имеют такую форму, что введение для них корреляционного радиуса является довольно грубой аппроксимацией. Поэтому определение значения среднего размера домена на основе экспериментальных снимков довольно затруднительно.

На рис. 2, $a-d$ видно, что чем меньше степень переохлаждения, тем большее расхождение наблюдается между теорией и экспериментом. Это связано с тем, что в окрестности точки фазового перехода процесс формирования ДС в сегнетоэлектриках существенно зависит от дефектности кристалла, а это в данной 

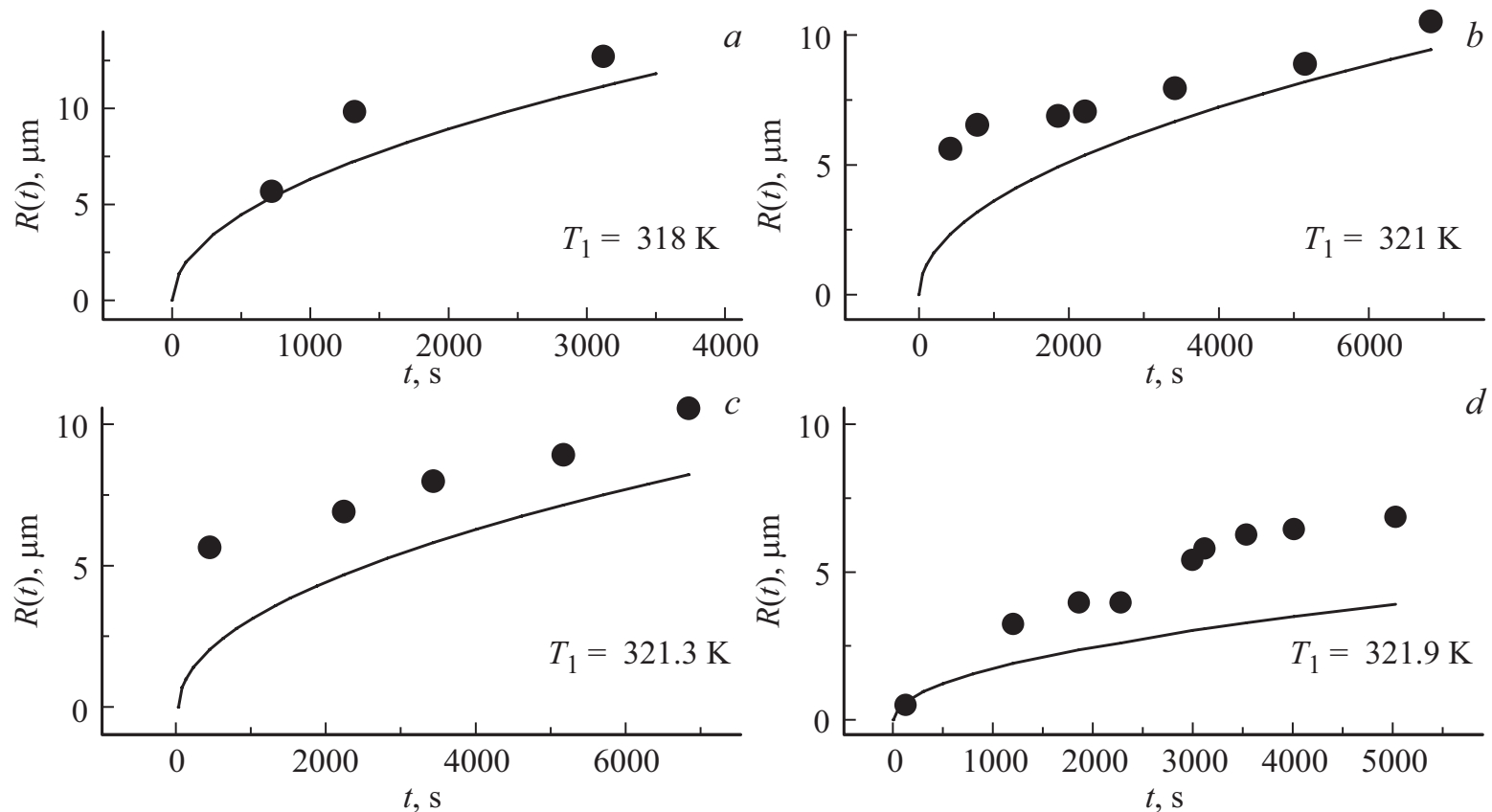

Рис. 2. Сплошными линиями изображены теоретические временные зависимости среднего размера домена для кристалла ТГС, отвечающие зависимости (1), для температуры переохлаждения $T_{1}: 318,321,321.3,321.9 \mathrm{~K}$ соответственно. Черными точками отмечены экспериментальные значения среднего размера домена в разные моменты времени, когда были сделаны мгновенные снимки релаксирующей доменной структуры [7,14-16].

работе не учитывалось. Поэтому сравнение наших теоретических зависимостей проводилось с экспериментальными результатами, полученными для номинально чистых кристаллов ТГС [7,15-16]. Но даже в таких образцах присутствуют дефекты, способные существенным образом влиять на релаксационные процессы. Эксперименты показывают, что присутствие дефектов и примесей повышает неоднородность системы, создавая „благоприятные“ зоны для роста доменов разных знаков. Препятствуя прорастанию доменов, дефекты-,,стопоры“ способны замедлять релаксацию ДС [10]. При этом вблизи $T_{C}$ доменные стенки являются довольно размытыми и поэтому могут проходить относительно небольшие расстояния к местам своего равновесного положения, „не чувствуя“ присутствия дефектов [14]. Поскольку данные аспекты не были учтены в развитой модели, характерный размер доменов в эксперименте растет быстрее, чем в теории, однако закон их роста близок к корневому (1) (рис. 2, $a-d$ ).

Ранее авторами данной работы уже исследовалась кинетика упорядочения в сегнетоэлектриках в зависимости от глубины переохлаждения $\alpha$ для больших глубин переохлаждения (на несколько Кельвин ниже $T_{C}$ ) [3], когда эволюция доменной структуры происходит сравнительно быстро. В настоящей работе этот анализ проводился для неглубоких охлаждений (от 0.1 до $4 \mathrm{~K}$ ), которые были использованы в экспериментах [7,14-16]. Для этого была модифицирована предложенная нами в [3] система уравнений для средней поляризации $\bar{\pi}(t)$ и ее дисперсии
$D(t)$, а именно мы полагали, что на стадии релаксации системы к термодинамическому равновесию внешнее электрическое поле на образец не действует. Аналитическое рассмотрение полученной системы предполагает нахождение особых точек и построение фазового портрета, аналогично тому, как и в [3]. В результате была теоретически подтверждена связь дисперсии с параметром переохлаждения $d \sim \alpha$, которая наблюдалось экспериментально в [6].

Построенные численными методами параметрические кривые на фазовом портрете для кристалла ТГС (рис. $3, a$ ) показывают, что вблизи $T_{C}$ система эволюционирует к стабильной полидоменной структуре независимо от глубины переохлаждения. Однако, этот параметр определяет траекторию эволюции системы. Видно, что при более глубоком охлаждении неравновесная система по мере релаксации вначале стремится к монодоменному состоянию (кривая 1 на рис. $3, a$ ), хотя в конечном итоге все равно формирует стабильное полидоменное упорядочение. Это стремление к монодоменному состоянию проявляется в виде резких максимумов на кривых 1,2 и 3 (рис. $3, b$ ), которые характеризуют кинетическое торможение системы вблизи седловой точки [3], а на самом деле они имеют вид ступеней или плато, если их построить в ином масштабе, что хорошо прослеживается на кривых 4 и 5 (рис. $3, b$ ). Время жизни подобной квазистационарной асимметричной полидоменной структуры может достигать нескольких минут, в зависимости от условий охлаждения [3]. 

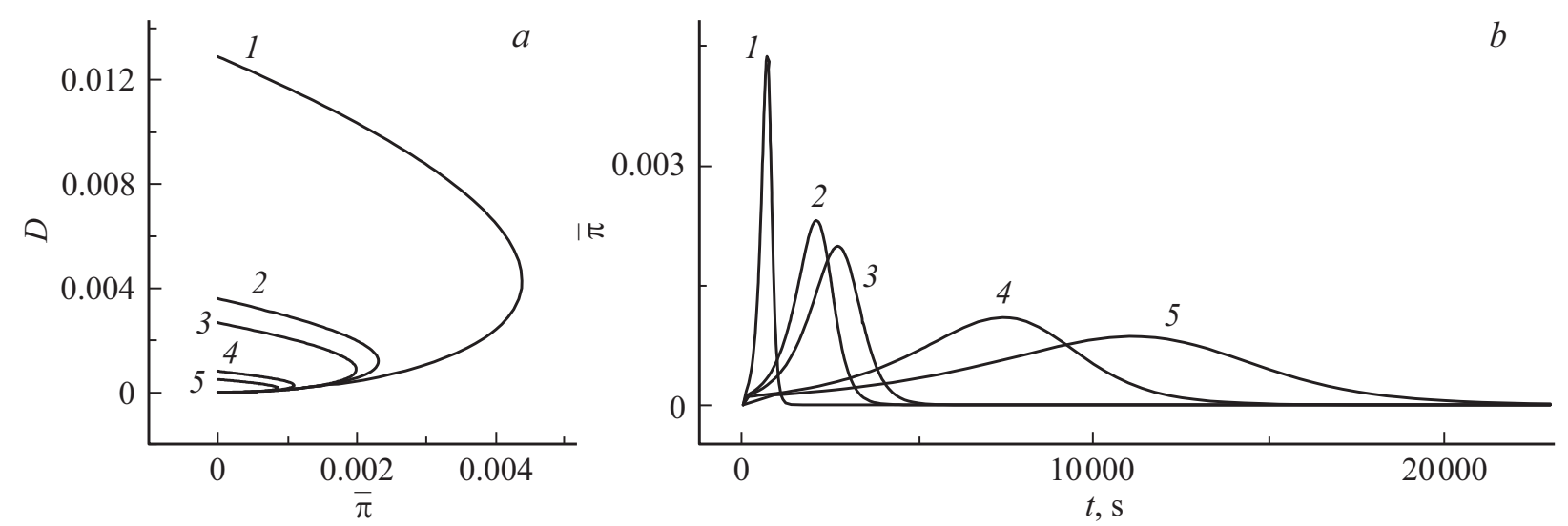

Рис. 3. $a-$ фазовые траектории системы при следующих значениях параметров: $r_{c}(0)=2, \bar{\pi}_{0}=0, D_{0}=0.0001$. Кривые $1-5$ отвечают значениям температуры охлаждения $T_{1}:\{318,321,321.3,321.9,322 \mathrm{~K}\}$ соответственно; $b-$ эволюционные кривые (в реальном времени) для средней поляризации $\bar{\pi}(t)$ при тех же значениях параметров и начальных условиях, что и на рис. $3, a$.

Кривые эволюции поляризации на рис. $3, b$ показывают, что в процессе релаксации система испытывает существенные доменные перестройки, в результате которых могут формироваться доменные структуры различного типа. При глубоком переохлаждении все процессы перехода к состоянию термодинамического равновесия (кривые $1-3$ на рис. $3, b$ ) протекают значительно быстрее. Чем ближе температура наблюдения $T_{1}$ к температуре фазового перехода, $T_{C}$, тем дольше система стремится сохранить неоднородности поляризации, возникшие непосредственно после перехода через $T_{C}$ (кривые 4,5 на рис. $3, b$ ). В этом случае наблюдается незначительное превалирование объемной доли доменов одного знака над объемной долей доменов другого знака, а также процесс перехода системы к равновесному состоянию является более длительным.

\section{4. Заключение}

В настоящей работе на примере кристалла ТГС рассмотрена эволюция доменной структуры быстроохлажденной сильнонеравновесной сегнетоэлектрической системы в окрестности температуры фазового перехода. Было установлено, что релаксационные процессы в кристаллах сегнетоэлектриков в процессе перехода к термодинамическому равновесию подчиняются некоторым общим закономерностям.

На основе развитого ранее [3] статистического подхода была получена временная зависимость $\bar{R}_{d}(t)$, которая показывает, что средний размер доменов растет по закону квадратного корня. В то же время установлено, что скорость роста доменного размера зависит от глубины переохлаждения по закону обратного корня $\left(\dot{\bar{R}}_{d} \sim 1 \sqrt{\alpha}\right)$. Полученная в работе зависимость характерного среднего размера домена от времени позволяет определить радиус межмолекулярного взаимодействия исследуемых кристаллов.
Было установлено, что для малых глубин переохлаждения 0.1-4K ниже температуры Кюри неравновесная система всегда эволюционирует к полидоменной структуре. Величина параметра переохлаждения $\alpha$ оказывает влияние на скорость укрупнения доменной структуры и траекторию ее эволюции к состоянию термодинамического равновесия. Было показано, что чем глубже охлаждается образец, тем сильнее он проявляет склонность к монодоменному типу упорядочения. Как было показано нами в [3,4], для формирования же монодоменной структуры при малых глубинах переохлаждения в процессе релаксации образец необходимо подвергать каким-либо внешним воздействиям.

Результаты наших исследования показывают, что при малых степенях переохлаждения размеры доменов растут медленнее, чем при более глубоком охлаждении. Было показано, что величина дисперсии поляризации, которая характеризует наличие в образце полидоменной структуры, пропорциональна параметру переохлаждения $D \sim \alpha$, что находит экспериментальное подтверждение.

\section{Список литературы}

[1] А.И. Никишина, С.Н. Дрождин, О.М. Голицына. ФТТ 48, 1073 (2006).

[2] В.Г. Вакс, В.И. Зиненко, В.Е. Шнейдер. УФН 141, 629 (1983).

[3] О.Ю. Мазур, Л.И. Стефанович, В.М. Юрченко. ФТТ 57, 562 (2015).

[4] О.Ю. Мазур, Л.И. Стефанович, В.М. Юрченко. ФТТ 57, 1358 (2015).

[5] N. Tomita, H. Orihara, Y. Ishibashi. J. Phys. Soc. Jpn. 58, 1190 (1989).

[6] E.Z. Luo, Z. Xie, J.B. Xu, I.H. Wilson. Phys. Rev. B 61, 203 (2000).

[7] О.М. Голицына, С.Н. Дрождин, А.Д. Коробова, В.О. Чулакова. Конденсированные среды и межфазные границы 19, 42 (2017). 
[8] М.С. Кособоков, В.Я. Шур, Е.А. Мингалиев, С.В. Авдошин. ФТT 57, 1967 (2015).

[9] В.И. Алтухов, И.С. Касьяненко, Б.А. Казаров, А.В. Санкин, С.В. Филлипова. Фундаментальные исследования 2, 708 (2015).

[10] О.М. Голицына, С.Н. Дрождин. ФТТ 53, 320 (2011).

[11] Т.А. Трюхан, Е.В. Стукова, С.В. Барышников. Физика и электроника 12, 97 (2010).

[12] М.Н. Левин, В.В. Постников, М.Ю. Палагин. ФТТ 45, 1680 (2003).

[13] М.А. Кривоглаз, А.А. Смирнов. Теория упорядочивающихся сплавов. ГИФМЛ, М. (1958). 388 с.

[14] О.М. Голицына, М.В. Гречкина, С.Н. Дрождин, В.О. Чулакова. Конденсированные среды и межфазные границы 18, 494 (2016).

[15] О.М. Голицына. Вестн. ВГУ Сер.: Физика. Математика 2, 54 (2013).

[16] С.Н. Дрождин, О.М. Голицына. ФТТ 54, 853 (2012).

Редактор К.В. Емцев 